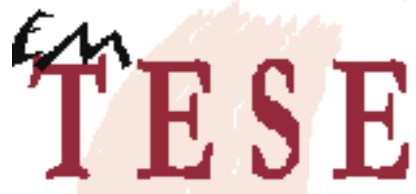

Revista Eletrônica dos Pós-Graduandos em Sociologia Política da UFSC

Vol. 5. n. 1 (1) agosto-dezembro/2008

ISSN 1806-5023

\section{O Sujeito Sem-Terra}

Suzana Maria Pozzer da Silveira ${ }^{1}$

\section{RESUMO}

Este artigo analisa as diferentes visões, em especial as mais polarizadas, sobre o sujeito no Movimento dos Trabalhadores Rurais Sem-Terra / MST. A partir destas, focando na temática do sujeito, e com base em estudo de caso de assentamento do MST, procura explicar quem é o sujeito sem-terra, suas características e potencialidades, amparada na análise das entrevistas concedidas pelos assentados.

\begin{abstract}
This article analyzes the different perceptions - specially the more polarized views - of the subject in the Landless Worker's Movement of Brazil (MST). Thus, by focusing on conceptions of the subject and basing the research on a MST settlement case study, this article attempts to explain who the landless subject is, and what are his/her characteristics and potentials. This is done by analyzing interviews given by the settlers themselves.
\end{abstract}

Palavras-chaves: sem-terra, sujeito, autonomia

Key words: landless, subject, autonomy

1 Doutoranda em Sociologia Política. Programa de Pós - Graduação da Universidade Federal de Santa Catarina / UFSC.

E-mail: sumapozzer@gmail.com

EmTese, Vol. 5 n. 1 (1), agosto-dezembro/2008, p. 49-73 


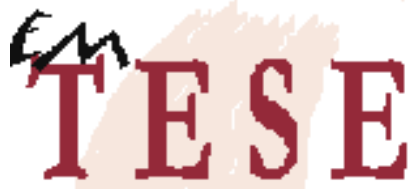

Revista Eletrônica dos Pós-Graduandos em Sociologia Política da UFSC

Vol. 5. n. 1 (1) agosto-dezembro/2008

ISSN 1806-5023

\section{1- INTRODUÇÃO}

O Movimento dos Trabalhadores Rurais Sem-Terra (MST) surge em 1984. Desde sua criação tem se expandido no território nacional, assim como se tornou um dos maiores movimentos presentes no âmbito rural da América Latina. Nas análises/estudos desse movimento, em especial oriundas da sociologia, tem surgido diferentes olhares em relação à atuação, organização e bandeiras de luta do MST. Para alguns autores o MST não conseguiu acabar, mesmo em relação aos seus membros, com as formas de tutela existentes no meio rural brasileiro. Estas teriam apenas mudado de forma, no sentido de que inexiste sujeito autônomo no movimento, devido a forte presença do centralismo democrático e dos mediadores ${ }^{2}$, os quais falam em nome do camponês. Já para outros, o MST teria desenvolvido uma forma própria de educar e gestar sujeitos sociais, com autonomia e conscientes de suas ações, entendendo que a luta do movimento transcende a questão da terra.

Face ao exposto, este artigo (tendo por base pesquisa de um assentamento do $\mathrm{MST}^{3}$ ) visa contribuir para o esclarecimento dessa dualidade de percepções do sujeito sem-terra. Para tal utiliza como critérios de análise, principalmente, a participação dos assentados, tanto no assentamento, quanto no movimento, verificando entre outros aspectos: a visão que possuem do MST, da reforma agrária; o discernimento necessário para tomada de decisões; a autonomia para a organização do trabalho, entre outros. Em função de referirem-se a um estudo de caso estes dados não poderão ser generalizados para o movimento como um todo, mas podem servir como referência comparativa, seja

2 Mediadores: lideranças do MST, as quais podem ser: nacional, regional ou local (representantes dos assentamentos e/ou acampamentos).

3 Dissertação de mestrado elaborada pela autora, tendo por título - A construção do sujeito no MST: Assentamento Eldorado dos Carajás, defendida em abril de 2007.

EmTese, Vol. 5 n. 1 (1), agosto-dezembro/2008, p. 49-73 


\section{留ESE}

Revista Eletrônica dos Pós-Graduandos em Sociologia Política da UFSC

Vol. 5. n. 1 (1) agosto-dezembro/2008

ISSN 1806-5023

para com outros assentamentos do MST, assim como outros movimentos sociais rurais, por exemplo.

\section{2- MST: DIFERENTES ABORDAGENS}

Na primeira abordagem destacaremos a versão dos autores Zander Navarro e José de Souza Martins que argumentam pela inexistência de sujeito autônomo no MST. Posteriormente, no item 2.2 em contraste a esta abordagem, Roseli Caldart e Martins Horácio Carvalho defendem que o MST tem um papel fundamental na constituição de sujeitos, em especial daqueles que estão em situação subalterna e de exclusão.

\section{1 - Primeira Abordagem}

Para essa análise o MST tem dificuldade de propiciar a formação de sujeitos autônomos, tendo como conseqüência um nível baixo de democratização nas relações entre os integrantes do movimento, assim como em relação a outros movimentos sociais.

Segundo a análise de Navarro (2002) o MST nasceu como um movimento social, tendo capacidade de se "reinventar", aglutinando setores mais pobres do meio rural. Teve forte apoio e influência de setores progressistas, principalmente, da Igreja Católica, através da Comissão Pastoral da Terra (CPT). Nesta fase, o movimento constituía-se democraticamente, sendo pouco hierarquizado, com participação da base nas decisões e ações. Posteriormente, devido vários fatores, o MST passou a ser uma organização, ou seja, não mais com participação de todos os envolvidos (base), mas 


\section{管ESE}

Revista Eletrônica dos Pós-Graduandos em Sociologia Política da UFSC

Vol. 5. n. 1 (1) agosto-dezembro/2008

ISSN 1806-5023

com forte centralização da tomada de decisões (mediadores, lideranças). Dessa fase em diante, a base do movimento passou a ser mobilizada por diversos aspectos, mas não pela sua "adesão consciente e voluntária". Sendo assim, argumenta que o movimento não contribui para a real emancipação dos pobres no campo, a qual tem por significado:

[...] às chances de as classes subalternas e os grupos sociais mais pobres, a partir de diferentes identidades, construírem, de forma autônoma, suas diversas formas de associação e representação de interesse e, mais relevante, adentrarem o campo das disputas políticas e aí exercerem seu direito legítimo de defender reivindicações próprias e buscar materializar suas demandas, sem o risco de eliminação ou constrangimentos politicamente ilegítimos materializados por grupos sociais adversários (NAVARRO, 2002, p. $196-197)$.

Desse modo o autor destaca que um dos principais desafios do movimento é a democracia, não somente interna ao movimento, mas também em relações a outros movimentos sociais, os quais o MST procura ter "controle" ou "fagocitá-los". As lideranças e mediadores, segundo o autor, vêem nas ocupações de terra potenciais de rupturas e transformações políticas, as quais não existem na percepção das famílias que lutam pela conquista da terra, dignidade, entre outros. Além disso, enfatiza que procuram inculcar no seio dos trabalhadores rurais uma perspectiva polarizada do mundo, reducionista, entre o bem e o mal.

$\mathrm{Na}$ sua perspectiva atualmente não é possível uma ruptura sociopolítica, assim como grandes transformações da sociedade. Desse modo, enfatiza que a possibilidade de real emancipação e transformação da sociedade passa pela radicalização da democracia e não pela política do "conflito pelo conflito". Dessa forma questiona: 


\section{T⿱⺈ $\mathrm{ESE}$}

Revista Eletrônica dos Pós-Graduandos em Sociologia Política da UFSC

Vol. 5. n. 1 (1) agosto-dezembro/2008

ISSN 1806-5023

[...] quando a organização permitirá, em "seus" assentamentos, que os próprios assentados decidam suas formas de cooperação (se não preferirem a ocupação familiar de suas parcelas específicas), como melhor entenderem (ou seja, respeitando-se sua autonomia) e, em particular, quando deixará de utilizar fundos públicos para exercer diferentes formas de controle social sobre as famílias instaladas nestas novas áreas? (Ibidem, 2002, p. 277).

Nesta mesma linha argumentativa, Martins (2003) esclarece que os camponeses não são, fundamentalmente, os protagonistas políticos da luta pela terra, uma vez que não possuem consciência política explícita, ou seja, para o autor a luta dos camponeses é “imediata pelo instrumento de trabalho necessário à sobrevivência”. Conforme suas palavras:

A dimensão propriamente política da questão agrária está no discurso e nas ações do que se pode chamar de agentes de mediação das lutas camponesas. São os grupos propriamente políticos, inspirados por doutrinas e ideologias partidárias, que interpretam a luta pela terra como luta pela reforma agrária. E não primariamente os trabalhadores rurais. Isto é, como luta política e luta de classes por uma revisão radical da estrutura fundiária do país, não raro em nome do socialismo. No geral, esses grupos de mediação são grupos de classe média, intelectuais, agentes religiosos e agentes partidários, educadores, ainda que dentre eles muitos tenham origem próxima ou remota em famílias camponesas, especialmente do Sul. É o caso de muitos dirigentes do MST e de muitos agentes da CPT (Ibidem, 2003, p.222-223).

Dessa forma, destaca que as lutas pela reforma agrária acabam não correspondendo aos anseios dos camponeses e as suas possibilidades de se autoorganizarem. Ou seja, os objetivos não são dos pobres, camponeses, mas da "classe média militante”. Frisa que primeiramente, havia certo desprezo em relação ao homem 


\section{管ESE}

Revista Eletrônica dos Pós-Graduandos em Sociologia Política da UFSC

Vol. 5. n. 1 (1) agosto-dezembro/2008

ISSN 1806-5023

do campo, como sendo alguém rude, ignorante, que está longe, distante do progresso. Posteriormente, da visão de desprezo passou-se a visão de tutela, ou seja, passam a ver o camponês como impossibilitado de ter voz, falar por si, que precisa de alguém que fale em seu nome. Destaca que esses mediadores, na maioria das vezes, procuram situar a questão da terra no âmbito da luta de classes e da luta antiimperialista, sendo que a maioria dos camponeses tem pouca compreensão do que seja esquerda e direita, comunismo, imperialismo, entre outros. Em síntese, enfatiza que os mediadores reproduzem uma "luta maniqueísta entre o bem e o mal" (Ibidem, 2003).

Mesmo com essas ressalvas, ambos os autores consideram o MST um movimento importante. Pois, ao organizar as populações mais pobres contribui, de certo modo, para a formação de relações mais democráticas no âmbito da sociedade rural.

\section{2- Segunda Abordagem}

Para essa análise o MST é um dos principais movimentos sociais do meio rural que mais consegue transformar indivíduos excluídos em sujeitos autônomos, com capacidade de esclarecimento e autodeterminação própria. Dessa forma, além de ser um movimento democrático, também contribui para avançar a radicalização da democracia na sociedade em geral.

Roseli Caldart (2001) destaca certas características do MST que o distinguem de outros movimentos sociais, tais como a sua capacidade de fazer com que pessoas excluídas da sociedade passem a ser lutadoras, se envolvam num processo de construção de novos significados para a sua realidade, assim como construtoras de novas relações sociais, em que prevaleça a solidariedade, o respeito às diferenças, o companheirismo, entre outros. Outro aspecto peculiar ao movimento, destacado pela autora, refere-se a radicalidade da forma de luta desenvolvida, no sentido de ocupar 


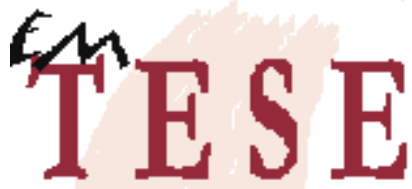

Revista Eletrônica dos Pós-Graduandos em Sociologia Política da UFSC

Vol. 5. n. 1 (1) agosto-dezembro/2008

ISSN 1806-5023

terras improdutivas e nelas construir acampamentos, envolvendo a família inteira, ou seja, a luta passa a ser de todos: homens, mulheres, jovens, crianças. Essas características, segundo a autora, fazem com que as demais pessoas externas ao movimento geralmente não fiquem indiferentes. Passam a se envolver de certa forma com o movimento, seja para apoiá-lo ou para denegri-lo. Enfatiza que o eixo central da luta do MST é pela terra, mas que o movimento também desenvolve diferentes lutas paralelas no decorrer de sua trajetória.

Estas lutas, bem como o trabalho cotidiano em torno do que são suas metas, e que envolvem questões relacionadas à produção, à educação, à saúde, à cultura, aos direitos humanos..., se ampliam à medida que se aprofunda o próprio processo de humanização de seus sujeitos, que se reconhecem cada vez mais como sujeitos de direitos, direitos de uma humanidade plena (Ibidem, 2001, p. 208).

Em relação à organização interna do movimento, ressalta que possui uma forma organizativa própria que, ao mesmo tempo, é flexível e permanente. Além disso, tem capacidade de abranger diferentes pessoas da sociedade, em geral, na luta por suas reivindicações. Consegue envolver os excluídos, organizando-os, ou seja, "não aceita a exclusão como um dado inevitável”. Questiona a lógica da sociedade atual pelo seu próprio modo de ser e aparecer, em marchas, acampamentos, fazendo do impossível o possível (permanecer famílias inteiras sob uma lona, durante meses, anos) e não pelas idéias revolucionárias, enfim é uma luta que pode ser sintetizada nas palavras de um sem terra: "Quando ocupamos aquela terra, paramos de morrer..."4.

4 (Domício, Sem Terra do Assentamento Ireno Alves, MST, antiga Fazenda Giacometti, Paraná, Brasil). In: CALDART, 2001. 


\section{管ESE}

Revista Eletrônica dos Pós-Graduandos em Sociologia Política da UFSC

Vol. 5. n. 1 (1) agosto-dezembro/2008

ISSN 1806-5023

Entende que o processo de estar em movimento constitui-se como um processo de formação humana, cuja "matriz é o próprio movimento como sujeito e princípio educativo". Ou seja, nas ações do movimento os indivíduos se constituem como sujeitos sociais, assim como demonstram aos demais, que estão excluídos da sociedade, que as mudanças são possíveis. Para a autora: "quanto mais inconformada com o atual estado de coisas, mais humana é a pessoa". Sendo assim, a participação no movimento cria "a possibilidade de fazer-se e refazer-se a si próprio".

Nesse sentido, no movimento tendo contato com outros sujeitos, com trajetórias parecidas, assim como com as lideranças/mediações os sem-terra vão entendendo que não basta apenas a terra, mas que a luta é muito mais ampla e que envolve uma série de fatores: sócio-históricos, econômico, entre outros. O debate desses temas com os mediadores/lideranças tende a propiciar uma melhor compreensão do contexto social, com suas particularidades, características, etc. Para tanto, além do apoio dos mediadores, a autora aponta a importância da educação para o "desenvolvimento de sujeitos políticos" que passam a compreender as lutas históricas dos trabalhadores por direitos. Explica que ao "transcender a questão da terra, a luta torna-se maior que ela mesma”.

Segundo a análise de Carvalho (2002), o MST constitui-se como um dos maiores movimentos sociais de massa do Brasil e também da América Latina. Destaca que mesmo tendo diferentes forças na sociedade contrárias a sua ação, tais como polícias militares; forças paramilitares (jagunços, pistoleiros); classes dominantes (capital agrário, comercial, industrial e bancário); grande parte dos meios de comunicação de massa, entre outros, o movimento consegue mobilizar milhões de agricultores sem-terra, obrigando o Estado e as "classes dominantes a colocarem a reforma agrária como uma das prioridades nacionais". 


\section{管ESE}

Revista Eletrônica dos Pós-Graduandos em Sociologia Política da UFSC

Vol. 5. n. 1 (1) agosto-dezembro/2008

ISSN 1806-5023

Para entender como o MST, com tamanhas dificuldades consegue êxito na sua luta, em função de seu crescimento e atuação em diferentes regiões do país, o autor enfatiza que é necessário compreender os "segredos intimos" do movimento, os quais propiciam a emancipação das "classes subalternas do campo" de diferentes formas de tutela, assim como a sua própria emancipação em relação a diferentes mediadores (Igreja, Sindicatos, Partidos, etc). A emancipação social referida significa um processo continuado, ou seja, algo que está em movimento permanente, uma vez que as relações de tutela não se acabam radicalmente, ou, se terminam umas, outras se apresentam e assim sucessivamente.

Conforme o autor, a "emancipação social continuada" não necessariamente exige a presença dos mediadores, pois os próprios integrantes do movimento, através de sua ação, mobilização pelos propósitos objetivos e subjetivos, acabam se emancipando nesse processo. O MST foi capaz de propiciar um novo sentido a essa emancipação, reafirmando a identidade dos sem-terra, a sua conquista de dignidade, fatores estes que contribuíram para a aquisição da cidadania. Além disso, também foram importantes para o empoderamento desses sujeitos as ações diretas, ocupações, pedagogia própria, mística, formação de novas relações, tanto internamente (solidariedade, companheirismo, disciplina, estudo) como externamente (autônomas e não cooptadas) em relação a outros movimentos sociais, Estado, etc.

\section{3- O ESTUDO DE CASO}

O assentamento selecionado para a pesquisa localiza-se na Região de Lebon Régis - Assentamento Eldorado dos Carajás -, no Estado de Santa Catarina. A seleção desse local, entre os 131 existentes nesse Estado, decorreu em função do estudo exploratório 


\section{留ESE}

Revista Eletrônica dos Pós-Graduandos em Sociologia Política da UFSC

Vol. 5. n. 1 (1) agosto-dezembro/2008

ISSN 1806-5023

no conjunto de assentamentos na Região de Lebon Régis. Optamos por pesquisar este assentamento, pois percebemos que nele havia maior coesão organizacional, tanto referente à infra-estrutura, quanto ao grau de participação dos assentados nas questões pertinentes ao assentamento. Isso provavelmente seja decorrente do fato de ser um dos últimos assentamentos da região, o que facilitou aos novos assentados, pois aprenderam com a experiência dos mais antigos, a fim de não repetir erros na organização e condução do assentamento, nos seus vários aspectos (decisão do que plantar, segundo a composição do solo; organização interna, etc). Para coleta dos dados aplicamos uma entrevista estruturada seguida de observação participante. (Vide: SILVEIRA, 2007).

\section{Eixos de análise}

A fim de entender o sujeito sem-terra, tendo em conta as referidas abordagens, foram delimitados três eixos de análise: $1^{\mathrm{o}}$ Eixo - Sujeito (subjetividade, empoderamento, pertencimento); $2^{\mathrm{o}}$ Eixo - Autonomia (mediadores); $3^{\mathrm{o}}$ Eixo Democracia (estrutura). Esta divisão em diferentes eixos é de cunho mais didático, visto que se torna difícil na análise fazer uma nítida separação dos referidos temas, os quais se relacionam mutuamente. Em função da delimitação de espaço, este artigo foca mais no primeiro eixo, tendo ênfase limitada em relação aos demais (Vide: SILVEIRA, 2007).

\section{1- Sujeito}

\section{Subjetividade e Pertencimento}

Em relação à percepção do MST, observou-se que os entrevistados o vêem como "instrumento" para conseguir bens, tanto materiais (terreno, casa, sementes, etc) quanto 


\section{管ESE}

Revista Eletrônica dos Pós-Graduandos em Sociologia Política da UFSC

Vol. 5. n. 1 (1) agosto-dezembro/2008

ISSN 1806-5023

simbólico/pedagógicos (aprendizado da importância da organização popular para 'conseguir muito mais coisa', valorização da identidade rural, etc). Dessa forma, o movimento e em conseqüência as ocupações, os acampamentos são formas de organização que são positivas para os assentados, pois por meio destes conquistaram um espaço, tanto físico (terreno, etc) quanto subjetivo (auto-estima). Através desta, conforme fala do "Assentado B", se 'consegue respeito', o qual é imprescindível para ser Sujeito, no sentido de ser reconhecido pelos demais, ao invés de estar a mercê, seja desempregado ou submetido as relações de produção já estabelecidas.

Analisando o cotidiano, a convivência, o trabalho no assentamento percebe-se que os assentados constroem uma subjetividade própria do meio rural, peculiar à realidade concreta em que vivem. Para ser possível confirmar e procurar "medir" o quanto esses agricultores são sujeitos hoje, faz-se necessário análise de como se constituem como sujeitos autônomos, assim como da aplicação de uma referência comparativa do tipo: como era a vida antes e depois de entrar no MST; qual o potencial de empoderamento, de autodeterminação desses assentados; entre outros, conforme pode ser ilustrado pelos seus depoimentos:

Se eu te conto. Era uma vida sofrida, antes de vir pra cá dependia de morar no que é dos outros, pagando aluguel, dependia de tudo. Hoje não, graças a Deus não estamos mil maravilhas, né. Deu uma virada, pelo menos foi um giro de noventa graus. Porque não tenho nada contra a cidade, gosto de tudo, né. Nós morávamos na casa dos outros, alugada (Fraiburgo). Por exemplo: os filhos, a mulher tinha que manter que nem cachorrinho (preso). Era só aquele lotinho e nada mais. Hoje, não, temos a liberdade aqui. Lá não podia andar de qualquer jeito [...]. Eu acho que tenho mais liberdade agora, que por mais que tenha algumas cláusulas no contrato que não posso fazer, né, mesmo assim eu acho que tenho minha liberdade. Porque, por 


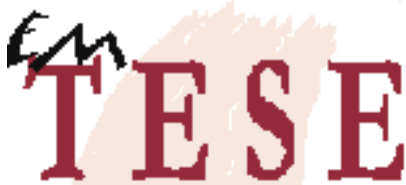

Revista Eletrônica dos Pós-Graduandos em Sociologia Política da UFSC

Vol. 5. n. 1 (1) agosto-dezembro/2008

ISSN 1806-5023

exemplo, se eu tivesse trabalhando fora como iria estar aqui agora para nós conversar, não é? ("Assentado B”).

Trabalhava em pomar de maça, depois que entrei no MST mudou, não tem hora marcada, a hora que você pode vai, se sente mais livre e mais a vontade ("Assentado F").

O grau de liberdade adquirido depois da conquista da terra é significativo, tanto em termos de decidir o que e como produzir (plantar) como em relação ao horário de trabalho. Além disso, o modo de portarem-se, de poder 'andar de qualquer jeito', conforme fala do "Assentado B", das crianças terem espaço para brincar, sem muito cuidado, tal qual exigia em terreno pequeno na cidade, faz com que tenham uma grau maior de liberdade.

Para o "Assentado C" o movimento contribuiu em diversos aspectos, tanto no seu aprendizado como pessoa, quanto em relação aos demais integrantes do grupo, conforme segue:

Antes de entrar no MST era difícil. De ter terra pra plantar, né. Pra mim melhorou bastante por isso. Antes trabalhava de peão. Agora tendo a terra pra você trabalhar, você planta o que quer. Vai pra roça a hora que quer. De empregado, peão, assim é diferente. [...] Acho que no movimento você aprende um monte de coisa, é uma aula para a pessoa. Tu aprendes muita coisa, né. Eu para começar, porque aula eu quase não fui. Porque dali quando entramos no acampamento, porque ficava meio que debalde. Tinha gente que pegava e fazia aula. Eu não sabia, mal a pena assinar meu nome. Só nesse sentido você aprende, né. E não fui só eu, foi um monte de gente. Desde estas jornadas que fomos, não é sair para fazer turismos. Desde o começo acho que o movimento foi bom para mim. [...] Não é eu para mim e você para você. Se tu tens tu come, se não tem fica sem, né. É muito diferente. Então é uma sociedade que é tudo junto. Nesse sentido, não 


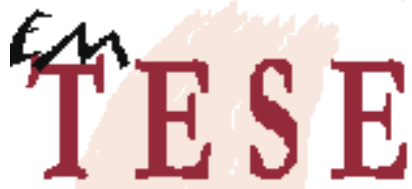

Revista Eletrônica dos Pós-Graduandos em Sociologia Política da UFSC

Vol. 5. n. 1 (1) agosto-dezembro/2008

ISSN 1806-5023

é assim individualmente, é pelo conjunto. Se estou aqui, porque eles me ajudaram e não só eles, né, também a sociedade ("Assentado C").

A liberdade, o maior espaço, a capacidade e possibilidade de decidir o que e como fazer na terra conquistada evidencia o grau de autonomia e subjetividade adquirido por esses assentados, principalmente em relação à vida que tinham antes, em que eram obrigados a vender sua força de trabalho e de submeterem-se as ordens do proprietário.

A fala do "Assentado C": 'Nesse sentido, não é assim individualmente, é pelo conjunto', revela que no movimento aprendem a se relacionar com os demais de outra forma, em que o coletivo é mais importante que o individual. Desenvolvem a capacidade de ser solidários, de dividirem quando necessário para que todos tenham dignidade. Outro aspecto da fala do "Assentado C": 'no movimento você aprende um monte de coisa, é uma aula para a pessoa’, ou seja, há uma significativa valorização do conhecimento adquirido no MST, no sentido positivo, de empoderamento do sujeito e não como algo tutelador, imposto.

A percepção, por parte do "Assentado D", do movimento como "um ser" solidário, que acolhe todos, assim como pelo seu papel fundamental na luta pela terra, segundo segue:

$\mathrm{O}$ movimento nunca virou as costas para ninguém, né. O assentado, se não fosse o movimento ele não conseguia. Porque não existe a pessoa entrar num terreno sem ter apoio de ninguém, né. Se tem o movimento eles vêm e conversam, tem tempo, mas sem o movimento os pistoleiros já tiram direto as pessoas do terreno ocupado, mal dá tempo para entrar. A luta do movimento vai além da aquisição da terra? Luta, o movimento não é só pelo terreno. Na verdade o movimento somos nós. Tem a liderança, né, mas quem faz o 


\section{留ESE}

Revista Eletrônica dos Pós-Graduandos em Sociologia Política da UFSC

Vol. 5. n. 1 (1) agosto-dezembro/2008

ISSN 1806-5023

movimento somos nós, né. O movimento é para conseguir o terreno e lutar por melhores condições de vida do assentado. Até se puder ajudar uns que estão na cidade, também, sempre na idéia da solidariedade, do não querer só pra si. Se tem movimento, o objetivo do movimento é sempre o coletivo, né, não individual. Sempre recursos para cooperativa, linha de leite, enfim um monte de coisa. Porque se lutasse só pelo terreno para o assentado, se não tem recurso como vai sobreviver em cima do terreno? ("Assentado D").

Conforme esclarece o "Assentado D" é meio difícil os agricultores conseguirem êxitos em suas lutas, sem o suporte do movimento, assim como desenvolver-se autonomamente, principalmente, num meio social que não propicia isso, tal qual o meio rural brasileiro, em que a violência e os maus tratos são freqüentes ao trabalhador rural. Além disso, são geralmente estigmatizados pela mídia como baderneiros, desocupados, etc. Dessa forma, os assentados vêem o movimento como um amparo, uma forma de se incluir socialmente, que os propicia tornarem-se ator capaz de ir construindo o movimento, ou reconstruindo-o, ou seja, como explica o referido assentado: 'quem faz o movimento somos nós'.

\section{Empoderamento}

No aspecto do empoderamento, no sentido de não ser apenas um sem-terra, mas um Sem-Terra:

Por exemplo, você está lá no Banco, a gente tem uma pastinha verde que os assentado usam - vai bloco de nota e coisa - então você chega lá e os caras já te conhecem pelo caminhar. Mas se chegar lá tipo um Mello da vida, já é tratado de outra forma (“Assentado B”). 


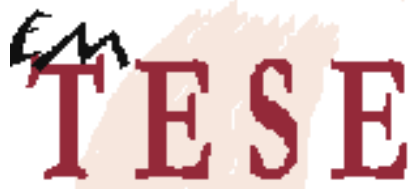

Revista Eletrônica dos Pós-Graduandos em Sociologia Política da UFSC

Vol. 5. n. 1 (1) agosto-dezembro/2008

ISSN 1806-5023

Ou seja, o movimento propicia empoderamento, pertencimento/inclusão aos assentados e, com isso, fortalece suas subjetividades, como fica explícito na fala do “Assentado B" em que se sente mais forte, "mais sujeito", pois já não é um qualquer ('um Mello da vida), mas um assentado do MST que sabe dos seus direitos, que faz parte de um dos maiores movimento do Brasil, que tem alcançado muitos êxitos, a ponto de lhe auxiliar, assim como tantas outras famílias, a conseguir terra, casa própria, trabalho e ter uma vida digna com seu familiares.

Esclarecem que no movimento passaram a compreender as raízes da concentração de terras no Brasil, assim como os principais empecilhos para acabar com o latifúndio, entre outros. Dessa forma, opinam sobre a proposta de reforma agrária do movimento e a existente hoje. Têm consciência que ainda falta muito para o MST conseguir efetivar a "sua reforma agrária". Compreendem que é somente pela ação e pressão do coletivo organizado que a mesma será implementada, ou seja, não basta constar na legislação que todos devem ter direitos a terra, saúde, educação. Para realmente a reforma agrária ser posta em prática faz-se necessário a organização e mobilização conforme mencionam:

Hoje ela está numa linha quase boa. O Lula tem a proposta de não só dar a terra, mas dar a terra e a infra-estrutura. Eu acho que está no caminho certo, mas falta muito ainda. Por isso que depende de nossas lutas, só que a gente não pode ficar em casa aqui sentado esperando que eles vão trazer. Se nós não formos à luta, em busca, quem pressiona lá o presidente é que vai ter mais coisas. Se a UDR, os ricos, irem lá e fazerem mais projetos, o presidente vai ter que atender quem tiver mais ("Assentado A"). 


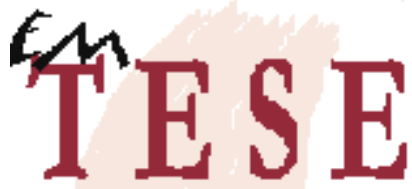

Revista Eletrônica dos Pós-Graduandos em Sociologia Política da UFSC

Vol. 5. n. 1 (1) agosto-dezembro/2008

ISSN 1806-5023

É que o governo veja mais o lado dos agricultores, né. Que nem eu falei, só conseguir o terreno não adianta. Que nem entra lá um governo que não apóia o pequeno agricultor não tem volta, não vê crédito nenhum. $\mathrm{O}$ cara só vai fazendo financiamento no banco, vai se endividando (“Assentado D”).

Além disso, enfatizam que não basta a terra, mas que é necessário o apoio, incentivo do governo para aquisição de sementes, adubos, enfim, condições para produzir e, dessa forma, se manter no meio rural.

\section{Considerações}

Conforme TOURAINE (1994) a subjetivação (que propicia a "libertação" do ser humano a toda a forma de dependência, assim como a transformação parcial do indivíduo em sujeito) e a autonomia (no sentido de decidir sobre sua vida, sem a imposição de papéis) fazem com que o indivíduo torne-se sujeito. Sendo assim, podemse caracterizar os assentados como sujeitos em construção, os quais foram na trajetória de acampados, depois assentados, conquistando autonomia e, com isso, vão tornando-se atores de suas próprias vidas. Dessa forma, o processo de fazer parte do movimento, assim como auxiliar a construí-lo propiciou um significativo empoderamento, tanto referente a subjetividade (auto-estima; identidade; solidariedade) quanto ao aprendizado em termos informacionais (entender o que é a reforma agrária, a origem, características e diretrizes do movimento, entre outros). A compreensão destas questões ocorre mais pela experiência, pela interação coletiva em reuniões, encontros, marchas e congressos do MST e não tanto pelo estudo e formação individual. Nesse processo, os assentados vão interagindo e construindo-se como sujeitos. Além disso, constatamos que a maioria dos assentados tem discurso próprio, no sentido de entenderem o que é melhor para o 


\section{T⿱⺈ $\mathrm{TSE}$}

Revista Eletrônica dos Pós-Graduandos em Sociologia Política da UFSC

Vol. 5. n. 1 (1) agosto-dezembro/2008

ISSN 1806-5023

assentamento, assim como os propósitos do movimento, a importância da reforma agrária e, dessa forma, possuem capacidade de, como diz Castoriadis (1982), "advir sobre o discurso do outro, não aceitar dominar-se pelo discurso do outro."

\section{2 - Autonomia}

\section{Os mediadores e os assentados}

As relações dos assentados com os mediadores, diferente da abordagem crítica ao movimento, conforme referido, é de muita liberdade de discutir, discordar, fazendo com que os assentados tenham voz ativa nas assembléias, negociações, etc. Além disso, costumam cobrar/fiscalizar os mediadores para que exerçam suas funções (de levar e trazer informações, de encaminhar propostas aos órgãos competentes, entre outros). Caso contrário, se não conseguirem se adequar ao estabelecido em assembléia pelos assentados, os mediadores são afastados ou perdem a credibilidade, conforme menciona o "Assentado B":

Tem encontros mensais, depende deles lá, né (Pena Branca.......) se precisam de nós e tem algum informe eles tão vindo aí. $O s$ mediadores costumam impor suas idéias e propostas, as quais devem ser acatadas? Não, não, Deus o livre se fosse assim, daí não é um mediador é um ditador, né. Ditador nós não queremos, né. Participamos, não tem discriminação. Não existe e nem pode existir. Por exemplo: tem lá a Nega Cutia (posseira - integrante do núcleo dois). Então quando nós chegamos aqui, ela queria meio que ditar as ordens. O pessoal recuou, não, não é assim como você pensa. Então, é um exemplo nosso mesmo. Não é qualquer um que vai chegar aqui e dizer o que temos de fazer, nem mesmo o Stedile. Se não serve não acatamos e o movimento não vai retaliar (“Assentado B"). 


\section{管ESE}

Revista Eletrônica dos Pós-Graduandos em Sociologia Política da UFSC

Vol. 5. n. 1 (1) agosto-dezembro/2008

ISSN 1806-5023

$\mathrm{Na}$ fala do "Assentado B" percebe-se, diferente da abordagem de NAVARRO (2002), que há participação dos assentados (base) nas decisões a serem tomadas, assim como se sentem em condições de discordar, caso seja necessário. Dessa forma, também não foi possível perceber o diagnóstico de MARTINS (2003) de que alguém fala em nome do camponês, sendo este impossibilitado de ter voz, mas ao contrário, conforme outros trechos mencionados, o movimento propicia empoderamento aos camponeses, fazendo com que tenham mais voz. Por exemplo, na fala do "Assentado G”: 'Eu achei que melhorou bastante a questão de falar, de ter mais coragem`, ou ainda segundo a fala de um sem-terra de outro assentamento, incluído na análise de CALDART (2001): 'Quando ocupamos aquela terra, paramos de morrer... ', ou seja, passaram a ter voz, a ser sujeito, a "parar de morrer" justamente quando começam a participar no movimento. Dessa forma, os mediadores no assentamento analisado são vistos mais como auxílio, em termos de organização e não como alguém que fala em nome dos camponeses. Sendo assim, os assentados vêem com bons olhos os mediadores, no sentido de que são os responsáveis para buscar recursos, encaminhar projetos, entre outros. Enfim, para eles os mediadores são imprescindíveis.

Os assentados se envolvem de vários e diferentes modos nas questões diárias do assentamento. Há o reconhecimento por parte dos demais membros do assentamento, no sentido de que todos têm condições "intelectuais", de formação política, entre outros, para se preciso for substituir o mediador do núcleo, tomar decisões com outros "companheiros" e entidades em reuniões fora do assentamento, por exemplo, tal como esclarece o "Assentado D":

Quando eles não podem ir numa reunião, qualquer um de nós pode ir e depois repassar para o pessoal. Como funcionam relações com 


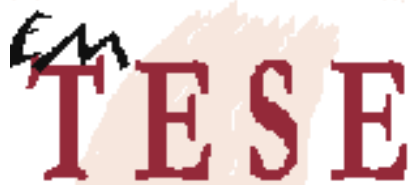

Revista Eletrônica dos Pós-Graduandos em Sociologia Política da UFSC

Vol. 5. n. 1 (1) agosto-dezembro/2008

ISSN 1806-5023

mediadores? Discordamos se necessário, porque, por exemplo, esse que era coordenador das 100 famílias, mas pra nós ele não representava nada, porque tinha reunião que passavam as coisas para ele e ele não ia, ou ia e não repassava as coisas para nós. ("Assentado D").

Dessa forma, constituem-se como sujeitos, que participam, interrogam, discordam e colaboram para a tomada de decisões que afetam suas vidas. Não são meros indivíduos, passivos, quase indiferentes à tomada de decisões pela direção, mas se sentem também direção. Não cabe mais a idéia de que o outro sabe mais, pode mais e, sendo assim, deve falar pelos assentados, mas sim que todos podem e que ninguém fala pelo outro, mas segundo o consentimento esclarecido do outro que o autorizou a falar.

\section{3- Democracia}

\section{A participação dos Assentados}

As assembléias no assentamento são para tratar dos problemas diários, do próprio assentamento, sendo que as discussões políticas acontecem mais em períodos eleitorais. A maioria dos assentados diz ser do Partido dos Trabalhadores (PT), sendo que há uma família do PMDB. Dizem-se do PT, em geral, ou seja, não são filiados a tendências políticas internas ao partido.

O movimento tem que puxar pelo lado dos trabalhadores. Na minha opinião apoiar um partido que está ao lado do movimento. Se ele está aqui assentado foi graças ao movimento, não foi outro. $O$ assentamento segue as diretrizes do MST na questão eleitoral? Nem tudo né, mas acho que a maioria. E esses que não seguem, tem alguma punição? Não acontece nada ("Assentado C”). 


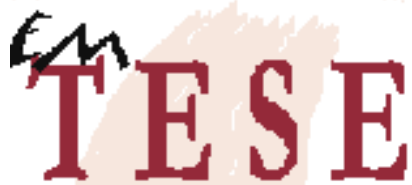

Revista Eletrônica dos Pós-Graduandos em Sociologia Política da UFSC

Vol. 5. n. 1 (1) agosto-dezembro/2008

ISSN $1806-5023$

Na fala do "Assentado C” o MST parece ser uma referência política, pedagógica e de apoio e não algo tutelador, pois caso fosse, os assentados teriam condições de identificar ou estaria implícito em suas falas. Da mesma forma que sabem identificar o patrão/fazendeiro como alguém que os explora e tutela, dificultando-os de serem sujeitos, também mencionariam os mediadores. Além disso, na fala dos assentados não se percebe a presença de um discurso ideologizado (politicamente correto), pois falam segundo suas experiências de vida, do sentir-se explorado, de não ter terra, enfim das dificuldades que passaram.

Em relação às diretrizes do MST em apoiar um candidato, não existe uma rigidez que todos devem seguir, mas geralmente seguem o movimento, nas principais decisões, de âmbito mais amplo (nacional ou regional). Até porque existe uma sintonia entre as decisões da coordenação do movimento e os assentados, conforme palavras do "Assentado A":

Vocês seguem as diretrizes do MST? Isso aí é começado aqui, é discutido aqui e vai indo, pela regional e depois vai para a estadual. Não é de cima para baixo, é o contrário, de baixo para cima. Não é o MST, a executiva, que decide apoiar um candidato e os demais tem que acatar, mas é de baixo para cima, dos acampamentos e assentamentos.

\section{A coordenação do assentamento}

No tocante a organização no assentamento, no sentido de distribuição de tarefas, entrada de novos membros, ocupação de cargos, verificou-se principalmente em relação 


\section{留ESE}

Revista Eletrônica dos Pós-Graduandos em Sociologia Política da UFSC

Vol. 5. n. 1 (1) agosto-dezembro/2008

ISSN 1806-5023

a este último que todos podem participar, ou seja, não existe restrição para ocupar um cargo, tal como coordenador de núcleo, por exemplo. Apenas deve ser indicado em Assembléia e se caso o indicado não aceitar será indicado outro membro.

Mesmo existindo atores mais centrais (coordenadores), os fluxos de informações não ficam centralizados nestes atores, pois caso isso aconteça, poderá ocorrer o afastamento do mediador do núcleo do assentamento. $\mathrm{O}$ mediador (coordenador do núcleo) deve repassar as informações aos demais. Da mesma forma em relação as decisões, ou seja, não é o mediador ou liderança que decide, mas o conjunto de assentados em assembléia. Face a isso e segundo o exposto, pode-se inferir que existe um significativo nível de democracia interna. Em outras palavras, está presente o poder descentralizado, a cultura do agir comum, a horizontalidade na tomada de decisões, aspectos estes que facilitam a formação de relações autônomas e democráticas.

\section{Considerações}

Pode-se destacar que predomina no assentamento um processo de organização democrático que favorece a autonomia e a subjetividade. Esses aspectos, no entanto, não estão presentes de forma absoluta, pois na realidade ninguém é totalmente autônomo e democrático, tendo em vista a heteronomia da própria sociedade. Além disso, algumas vezes, os interesses pessoais acabam prevalecendo em relação ao coletivo. Dessa forma, parece mais correto colocar que os assentados são indivíduos que ao participar do movimento vão constituindo-se como sujeitos autônomos através da prática de relações mais democráticas e, em conseqüência, diminuindo sua condição de tutelado.

EmTese, Vol. 5 n. 1 (1), agosto-dezembro/2008, p. 49-73 


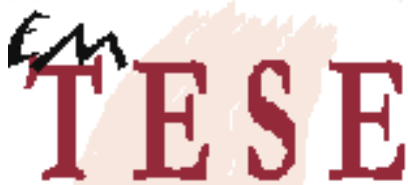

Revista Eletrônica dos Pós-Graduandos em Sociologia Política da UFSC

Vol. 5. n. 1 (1) agosto-dezembro/2008

ISSN 1806-5023

\section{4- CONSIDERAÇÕES FINAIS}

Segundo exposto alguns autores apontam que o MST reproduz junto a seus membros as tradicionais relações de tutela existentes no meio rural, sob outras formas. Isso decorrente do fato de que não seriam os camponeses os protagonistas, sujeitos capazes de se auto-organizarem, mas as lideranças, os dirigentes/mediadores que os conduziriam, através do discurso da utopia de uma outra sociedade, enquanto a luta dos camponeses seria apenas pela subsistência imediata.

Entretanto, tendo em vista a secular relação de subordinação e tutela pelas quais são vítimas os camponeses parece difícil conseguirem romper com essa lógica sem antes serem capazes de pensar, no sentido de imaginarem alternativas, ou seja, de que é possível a construção de novas formas de sociabilidade e de relações sociais, enfim compreenderem que a realidade social não é um dado imutável, mas que é construído e, portanto, passível de mudanças. Mas para isso, fundamental se torna um nível razoável de escolaridade, a fim de entenderem a engrenagem de funcionamento da sociedade, tanto nos aspectos históricos, sociais, econômicos, etc. No entanto, os camponeses carecem dessa formação o que dificulta a possibilidade de imaginarem alternativas e de se auto-organizarem de forma sustentável. Além disso, existe toda uma lógica na sociedade que não favorece a autonomia, a emancipação, o questionamento, pois predomina o poder econômico dos grandes proprietários, os quais geralmente integram o setor dominante, no sentido de possuírem muito poder no âmbito do Estado, dos meios de comunicação e do mercado. Dessa forma, a autonomia dos camponeses vai se consolidando, através da participação no movimento, pois é neste e através deste que vão entendendo porque são sem-terra, sem trabalho, sem cidadania, entre outros. Assim como, possibilita-os imaginar que a realidade pode ser diferente, seja pela construção de 


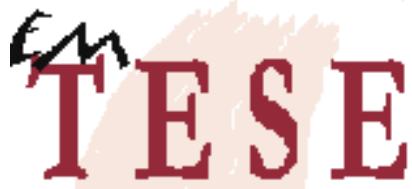

Revista Eletrônica dos Pós-Graduandos em Sociologia Política da UFSC

Vol. 5. n. 1 (1) agosto-dezembro/2008

ISSN 1806-5023

novas relações sociais, da práxis do pensar e atuar coletivo, da valorização da identidade rural, enfim fatores que vão constituindo-os como sujeitos. Daí a importância do movimento e de tudo o que o constitui (mediadores, educação, simbologias, tradições, etc).

Nesse sentido cabe destacar, como base para o referido entendimento, a análise de Alain Touraine (1994) quando enfatiza que "o sujeito somente existe como movimento social, por seu caráter contestatório à lógica da ordem”. Ou seja, são os movimentos sociais que propiciam com mais vigor o engajamento que protesta contra as exclusões existentes na sociedade e, como conseqüência, tem mais possibilidade de propiciar a formação de sujeitos, em especial dos excluídos e estigmatizados.

Sendo assim, entende-se que os mediadores não são um problema se integram o movimento na condição de facilitadores e aprendizes, tendo em vista que os camponeses também têm muito a ensinar, seja em função da experiência de vida, do trabalho no campo, da sabedoria popular, entre outros. Entretanto, no caso em que as mediações arrogam-se portadoras do "saber", seja do passado, presente quanto futuro e se entendem no direito de doutrinar e impor aos demais sua visão de mundo, aí neste caso já não é mais um movimento social, mas uma organização (hierárquicovanguardista), tal qual a afirmação de Navarro, ou até uma seita (muitos movimentos considerados como seitas, desmembram-se, cessam ou mudam de direção ideológica e/ou doutrinal com o desaparecimento dos seus líderes). Contudo, os indicativos dessa pesquisa apontam que o MST parece ir em outra direção. Pois, verificou-se que através do aprendizado da construção do sujeito devido o processo de estar no movimento, os assentados vão adquirindo a capacidade de questionar a situação opressiva e desigual, a qual os excluía do acesso à cidadania. Nesse sentido, a conquista da autonomia faz parte 


\section{留ESE}

Revista Eletrônica dos Pós-Graduandos em Sociologia Política da UFSC

Vol. 5. n. 1 (1) agosto-dezembro/2008

ISSN 1806-5023

desse processo de organização e luta por direitos. Constatou-se que integrado a essa luta, os mediadores atuam mais na condição de facilitadores e auxiliares, não significando que falam em nome dos camponeses tal qual aponta a crítica, pois são coadjuvantes na luta pela terra.

Face ao exposto, é possível afirmar que existe no assentamento uma "democracia viva", onde seus integrantes podem tomar decisões sobre suas vidas, assim como influir, em parte, nas decisões da sociedade em geral, através da participação, do envolvimento e com isso da compreensão que os fatos (contexto, relações, valores, etc) podem ser diferentes. No entanto, cabe destacar que fundamental e necessário para criar e, principalmente, manter os alicerces desta democracia, é o processo ininterrupto da constituição do sujeito, através do permanente desenvolvimento da auto-estima, da iniciativa, do empoderamento, a fim de que com isso continuem sendo capazes de criar e produzir de acordo com sua realidade e necessidades, não sendo meros consumidores e expectadores. Dessa forma, diferente da abordagem crítica ao movimento, esta pesquisa encontrou outros indicativos, os quais não são suficientes para caracterizar o movimento como um todo, mas que ilustram outras tendências, as quais podem ou não vir a ser corroboradas por outras pesquisas em diferentes assentamentos e acampamentos do MST. 


\section{留ESE}

Revista Eletrônica dos Pós-Graduandos em Sociologia Política da UFSC

Vol. 5. n. 1 (1) agosto-dezembro/2008

ISSN 1806-5023

\section{5- REFERÊNCIAS BIBLIOGRÁFICAS}

CALDART, Roseli Salete. O MST e a formação dos sem terra: o movimento social como princípio educativo. Estudos avançados, V.15, N. ${ }^{\circ}$ 43, São Paulo: 2001.

CARVALHO, Horácio Martins. A emancipação do movimento no movimento de emancipação social continuada (resposta a Zander Navarro). In: Santos, B.S.S [Org.] Produzir para viver: os caminhos da produção não capitalista. Rio de Janeiro: Civilização Brasileira, 2002.

CASTORIADIS, Cornelius. A instituição imaginária da sociedade. Rio de Janeiro: Paz e Terra, 1982.

MARTINS, J. Souza. O sujeito oculto: ordem e transgressão na reforma agrária. Porto Alegre: Editora da UFRGS, 2003.

NAVARRO, Zander. "Mobilização sem emancipação" - as lutas sociais dos sem-terra no Brasil. In: Santos, B.S.S [Org.] Produzir para viver: os caminhos da produção não capitalista. Rio de Janeiro: Civilização Brasileira, 2002.

O MST e a canonização da ação coletiva (resposta a Horácio Martins Carvalho). In: Santos, B.S.S [Org.] Produzir para viver: os caminhos da produção não capitalista. Rio de Janeiro: Civilização Brasileira, 2002.

SILVEIRA, Suzana M. P. A construção do sujeito no MST: Assentamento Eldorado dos Carajás. Dissertação de mestrado, defendida em abril de 2007. Programa de PósGraduação em Sociologia Política - Universidade Federal de Santa Catarina.

TOURAINE, Alain. Crítica da modernidade. Rio de Janeiro: Vozes, 1994. 